\title{
АЛМАЗЫ В ПРОДУКТАХ ИЗВЕРЖЕНИЯ ВУЛКАНА ТОЛБАЧИК (КАМЧАТКА, 2012-2013 ГГ.) И МЕХАНИЗМ ИХ ОБРАЗОВАНИЯ
}

\author{
(C) 2016 г. Э. М. Галимов ${ }^{a *}$, Г. А. Карпов ${ }^{b * *}$, В. С. Севастьянов ${ }^{a}$, \\ С. Н. Шилобреева ${ }^{a}$, А. П. Максимов ${ }^{b}$ \\ ${ }^{a}$ Институт геохимии и аналитической химии им. В.И. Вернадского РАН \\ 119991 Москва, ул. Косыгина, 19 \\ ${ }^{b}$ Институт Вулканологии и Сейсмологии ДВО РАН \\ 683006 Петропавловск-Камчатский, бул. Пийпа, 9 \\ *e-mail: galimov@geokhi.ru \\ **e-mail:volcan@kscnet.ru \\ Поступила в редакцию 29.04.2016 г. \\ Принята к печати 05.05.2016 г.
}

\begin{abstract}
Происхождение алмазов, найденных в лаве и пепле недавнего извержения (2012-2013 гг.) вулкана Толбачик на Камчатке, загадочно. В минеральном составе вмещающих пород нет никаких признаков существования высокого давления, которое необходимо для образования алмазов. Мы изучили изотопный состав углерода алмазов и дисперсного углерода в лаве Толбачика, который мог служить субстратом для синтеза алмазов, и установили, что они схожи. Есть свидетельства того, что формирование алмазов Толбачика связано с динамикой флюида. На основании полученных результатов предполагается, что микроалмазы Толбачика образовались в процессе кавитации, возникшем при быстром движении вулканического флюида. Ранее нами была показана теоретическая возможность образования алмазов в процессе кавитации, и эта гипотеза была подтверждена экспериментально. Ультравысокое давление при кавитации создается в локальных точках (схлопывающиеся пузырьки); при этом давление окружающей среды не является определяющим для синтеза алмаза. Условия возникновения кавитации достаточно обычны в геологических процессах. Поэтому микроалмазы подобного происхождения могут быть распространены в природе гораздо шире, чем это предполагалось ранее.
\end{abstract}

Ключевые слова: алмазы, синтез, вулкан, извержение, кавитация, изотопия углерода DOI: $10.7868 / \mathrm{S} 0016752516100034$

\section{ВВЕДЕНИЕ}

В продуктах недавнего (2012-2013 гг.) извержения вулкана Толбачик на Камчатке, были обнаружены микрокристаллические алмазы (Гордеев и др., 2014; Силаев и др., 2015). Из лавы и пепла были выделены сотни микрокристаллов размером 50-200 мкм, преимущественно желтозеленой окраски (рис. 1). Большинство кристаллов представлено куб-октаэдрами. Микрокристаллы, согласно описанию Силаева и др., (2015), характеризуются линией $1332 \mathrm{~cm}^{-1}$ в рамановском спектре и линиями 1345 и $1130 \mathrm{~cm}^{-1}$ в инфракрасном спектре поглощения, отвечающими структурным С-дефектам. Встречаются также ромбододекаэдры $\{110\}$ и тетрагон-три-октаэдры 131$\}$. Термическое окисление микроалмазов начинается при $750^{\circ} \mathrm{C}$.

Лавы, в которых обнаружены алмазы, имеют андезит-базальтовый и базальтовый состав. Алмазы обнаружены только в первых взрывных пор- циях пористой лавы и в пепловых отложениях, выбрасываемых с большой скоростью (пепел поднимался на высоту до 250 м).

Природа алмазов, найденных в продуктах извержения Толбачика, загадочна, также как и происхождение других некимберлитовых алмазов: для образования алмаза необходимо высокое давление, а признаки развития высоких давлений в минеральном составе вмещающих пород отсутствуют (Силаев и др., 2015).

Первое подробное описание некимберлитовых алмазов в базальтах (в том числе, в базальтах Камчатки) было сделано Ф.В. Каминским (Каминский, 1984). Алмазы нанометровых размеров были обнаружены в расплавных включениях ксенолита гранат-пироксеного состава (вебстерит) в Гавайских эффузивных породах (Wirth and Rocholl, 2003). Эти авторы особо отметили, что породы, содержавшие наноалмазы, не имели никаких признаков высокого давления (Wirth and Ro- 
choll, 2003). П. Картини (Cartigny, 2010) описал алмазы из коматиитов и карбонадо, происхождение которых также остается неясным. Любые физически приемлемые модели, объясняющие возникновение нетрадиционных алмазов, до сих пор не предложены, хотя авторы часто ссылаются на то, что газ, флюид и метасоматические процессы сыграли свою роль в образовании таких алмазов (Haggerty, 1986; Kaminskiy, 1994; Boyd et al., 1994; Navon, 1999; Cartigny et al., 2004).

\section{РЕЗУЛЬТАТЫ ИССЛЕДОВАНИЯ}

Мы измерили изотопный состав углерода алмазов Толбачика и углерода ассоциированных вулканических образований. Образцы пород были отобраны на Камчатке в 2014 г. во время полевых работ. Изотопный анализ проводили на масс-спектрометре Delta Plus. Данные представлены в виде значений $\delta^{13} \mathrm{C}-$ отклонений в \%о относительно стандарта PDB: ${ }^{13} \mathrm{C} /{ }^{12} \mathrm{C}=0.0112372$. Погрешность измерения не превышает $\pm 0.05 \%$. Измеренные значения изотопного состава углерода для 4 кристаллов алмаза изменялись в диапазоне от -25.55 до $-24.56 \%$ со средним значением $\delta^{13} \mathrm{C}=-25.05 \%$.

Дополнительно мы собрали образцы лавы и шлака на различном расстоянии от центра извержения Толбачика в 2012-2013 гг. (таблица). Концентрация углерода в образцах составляла $0.02-$ 0.05 мас. \%. Удалялся карбонатный углерод, но химическая форма восстановленного углерода в образцах не устанавливалась. Изотопный состав углерода был определен путем окисления образцов при $1100^{\circ} \mathrm{C}$. Полученные $\delta^{13} \mathrm{C}$ значения от -28.9 до $-25.3 \%$ близки к изотопному составу микроалмазов. Кроме того, мы изучили изотопный состав фумарольных газов и фильтрационных потоков углеводородов в кальдере вулкана Узон на Камчатке. Были получены средние значения $\delta^{13} \mathrm{C}$ метана $-24.0 \%$ (для углекислого газа

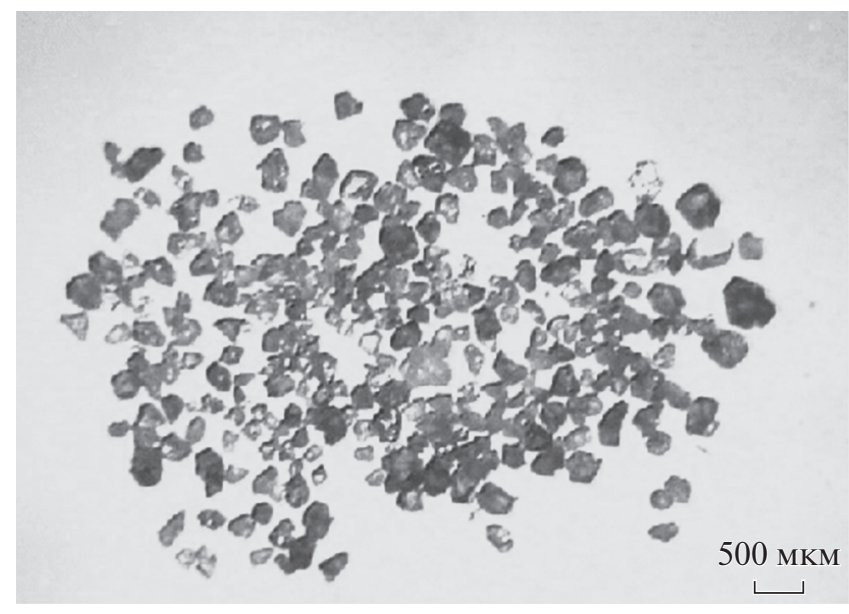

Рис. 1. Общий вид кристалликов микроалмаза, выделенных из продуктов Толбачинского извержения в 2012-2013 гг. (Карпов и др., 2014).

$-2.8 \%$ ). Величины $\delta^{13} \mathrm{C}$ углеводородов (нефтяных пленок в гидротермах) изменялись в диапазоне от -29.91 до $-31.24 \%$. Более детальная информация представлена в (Галимов и др., 2015). Примечательно, что изотопный состав углерода микро-алмазов находится в том же диапазоне, что и изотопный состав углерода в лаве и вулканических выделениях.

Генеральное распределение изотопного состава углерода алмазов из разных месторождений мира имеет бимодальный характер (Galimov, 1991). Оно характеризуется значением $\delta^{13} \mathrm{C}$ около $-5 \%$ для мантийных алмазов перидотитового парагенезиса и $\delta^{13} \mathrm{C}$ около $-7 \%$ для алмазов эклогитового парагенезиса. Последние имеют гораздо более широкий диапазон вариаций $\delta^{13} \mathrm{C}$ (рис. 2). Величины $\delta^{13} \mathrm{C}$ алмазов карбонадо изменяются, в основном, от -22 до -32\%о (Виноградов и др., 1966; Галимов и др., 1985; Cartigny et al., 2004). Алмазы из коматиитов (Dachin,

Содержание и изотопный состав углерода в лавах Толбачинского извержения 2012-2013 г.

\begin{tabular}{l|l|c|c}
\hline \multicolumn{1}{c|}{ Локализация* } & \multicolumn{1}{|c|}{ Описание } & мас. \% & $\delta^{13} \mathrm{C}_{\mathrm{PDB}}, \%$ o \\
\hline Поток Набоко, восточная часть & Лавовая корка & 0.02 & -26.60 \\
Поток Набоко, восточная часть & Закаленная лава & 0.03 & -25.29 \\
Прорыв Меняйлова, трещина & Шлаковая бомба & 0.02 & -26.60 \\
Поток Меняйлова & Плотный базальт & 0.03 & -28.93 \\
Поток Набоко & Базальт крупнопористый & 0.02 & -26.20 \\
Конус Набоко & Шлаковая бомба & 0.05 & -27.86 \\
Поток Набоко, восточная часть & Канатная лава & 0.02 & -26.22 \\
Поток Меняйлова & Плотный базальт & 0.02 & -25.84 \\
Конус Набоко & Шлаковая бомба & 0.03 & -27.56 \\
Конус Набоко & Пористая бомба & 0.03 & -26.41 \\
\hline
\end{tabular}

* Положение центров извержений и лавовых потоков прорывов Меняйлова и Набоко см. в работе (Волынец и др., 2013). 


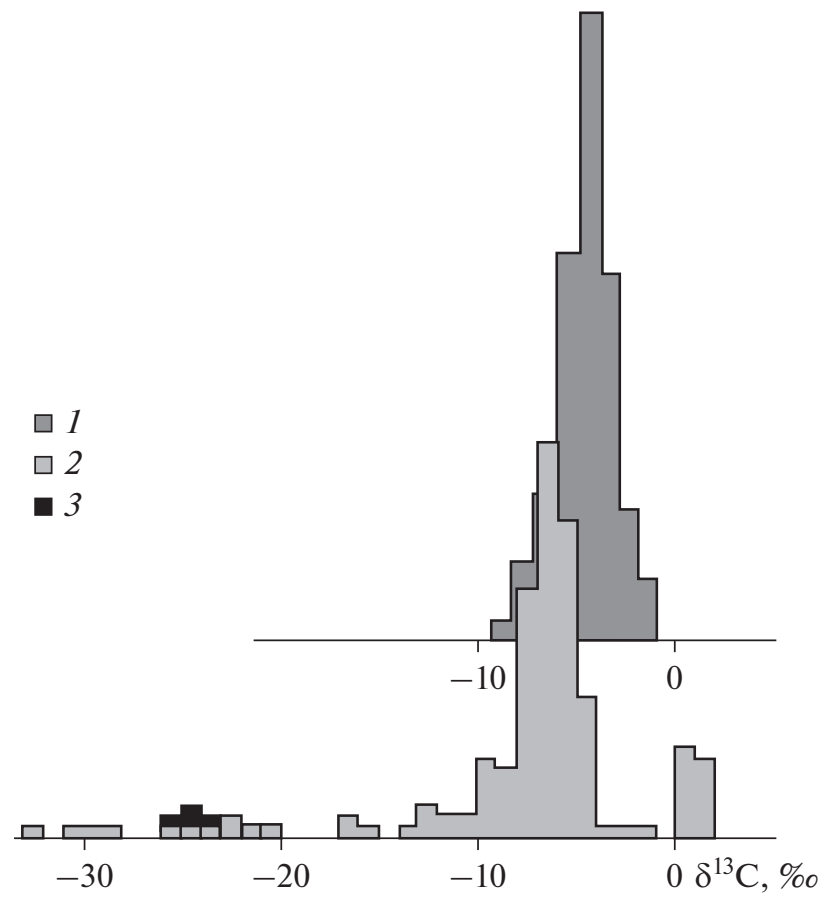

Рис. 2. Изотопный состав исследованных Толбачинских микрокристаллов на фоне гистограммы распределения изотопных составов алмазов перидотитового и эклогитового парагенезисов (Galimov, 1991): 1 - перидотитовый парагенезис, 2 - эклогитовый парагенезис, 3 - толбачинские алмазы.

Французская Гвиана) сходны по изотопному составу с карбонадо (Cartigny et al., 2004). Изученные алмазы Толбачика попали в тот же диапазон значений $\delta^{13} \mathrm{C}$, т.е. обогащены легким изотопом углерода по сравнению с мантийными кимберлитовыми алмазами перидотитового парагенезиса. Основываясь на полученных результатах и учитывая некоторые особенности наблюдаемого явления, рассматриваемые ниже, мы приходим к выводу, что изученные алмазы имеют специфическую природу, а именно образовались при возникновении режима кавитации в вулканическом флюиде. Гипотеза синтеза алмазов в процессе кавитации была предложена Э.М. Галимовым в 1973 г. (Galimov, 1973). Некоторые авторы сомневались в возможности этого процесса (Frank, 1973). Однако, кавитационный синтез алмазов был подтвержден экспериментально при возбуждении кавитации в углеродсодержащей жидкости (Galimov et al., 2004).

Как известно, кавитация возникает в жидкости при резком изменении внутреннего давления: к примеру, это происходит при работе гребных винтов судов, в трубопроводах и насосах. Чем выше относительная скорость потока, тем выше вероятность кавитации.

Что касается геологического процесса, то суть идеи заключалась в следующем. Известно, что образование алмазоносных кимберлитовых трубок происходит в результате быстрого подъема магматического флюида, прокладывающего путь из мантии к поверхности Земли через сравнительно узкий канал. Когда газонасыщенная магма под большим давлением достигает приповерхностных слоев, она выбрасывает колонку осадочных пород, образуя конусообразную структуру, которая заполняется кимберлитовой магмой. Эти структуры получили название трубок взрыва. При полной выработке алмазоносной кимберлитовой трубки геологи на дне часто обнаруживают подводящий канал.

Во время взрывного извержения расплав и флюид движутся быстро, о чем свидетельствует наличие обломков мантийных пород (ксенолитов), выносимых с глубины нескольких десятков километров (Dawson, 1980). Расчетная скорость потока расплава составляет, по крайней мере, 20 м/с (Perchuk et al., 1983); по некоторым оценкам она может превышать $100 \mathrm{~m} / \mathrm{c}$ (Ukhanov and Malysheva, 1973). В процессе прохождения жидкости в подводящем канале, имеющем, как правило, неправильную форму и переменное сечение, возникают значительные вариации давления в потоке. Согласно уравнению Бернулли, внутреннее давление в движущейся жидкости обратно пропорционально квадрату скорости потока. В сужающейся части канала скорость становится выше, и давление падает. Было показано, что давление может упасть ниже порога паро-газо-образования. В этом случае происходит образование газонаполненных пузырьков (Galimov, 1973). В расширяющейся части канала скорость уменьшается, давление в потоке восстанавливается, и пузырьки испытывают коллапс. Как известно, за счет генерации сферически сфокусированного гидравлического удара создается очень высокое давление при коллапсе пузырьков. Это - явление кавитации. Даже при нормальном атмосферном давлении (например, при схлопывании мелких пузырьков в воде) развивается пиковое давление до 10 кбар (Зельдович и Райзман, 1966). В условиях литосферы внешнее давление достигает тысяч атмосфер, и давление в центрах коллапсирующих пузырьков может значительно превзойти давление, необходимое для синтеза алмазов (Galimov, 1973). Современные расчеты показывают, что при атмосферном давлении более 0.2 кбар давление в схлопывающемся пузырьке может превышать 300 кбар, а температура увеличиваться до $2000^{\circ} \mathrm{C}$. Эти значения находятся в поле стабильности алмаза (Dnestrovski et al., 2011). $P$ - $T$ условия, достаточные для синтеза алмазов, сохраняются в течение около 20 нс. Расчеты проводились для условий успешного эксперимента в бензоле (Galimov et al., 2004) для пузырька с начальным размером $R=500$ мкм и внешним давлением 0.1 кбар. Для сравнения, при детонационном искусственном 
синтезе алмазов время действия высоких давлений оценивается примерно в 10 нс (Erskine and Nellis, 1991).

Применив этот механизм к случаю образования алмазов Толбачика, мы получаем правдоподобное объяснение ряда геохимических особенностей их формирования.

Во-первых, решается проблема, связанная с отсутствием минералов высокого давления. Согласно фазовой диаграмме, алмазы в условиях литосферы стабильны при давлении выше 4.5 гПа, что соответствует глубинам, превосходящим 150 км вдоль типичной геотермы. Андезит-базальтовая лава, которая является вмещающей породой для алмазов вулкана Толбачик, генерируется на значительно меньших глубинах. Кристаллы алмаза сохранили острые края, что исключает их существенный перенос в виде отдельных кристаллов. Кавитационная модель предполагает, что давление, необходимое для синтеза алмазов, создается в центре смыкающегося пузырька. Следовательно, величина внешнего давления не является критичной. Хотя она будет достаточно высокой в условиях земных недр, тем не менее, может оказаться значительно меньше давления, соответствуюшего термодинамической устойчивости алмаза и других минералов высокого давления.

Как следует из нашего исследования, изотопный состав углерода алмазов вулкана Толбачик схож с изотопным составом возможных углеродсодержащих субстратов, из которых могли формироваться алмазы в процессе кавитации. Алмазы характеризуются низкими значениями $\delta^{13} \mathrm{C}$, в среднем -25.05\%о. Углеводороды, в частности метан, являются подходящим субстратом для кавитационного синтеза алмазов. Экспериментально алмазы были получены в ходе возбуждения гидродинамической кавитации в бензоле (Galimov et al., 2004). Метан, один из компонентов вулканических газов, имеет изотопный состав $\left(\delta^{13} \mathrm{C}=-24.0 \%\right.$ ), сходный с изотопным составом алмазов. Другие углеводороды также близки по изотопному составу к исследованным алмазам. Еще более вероятным субстратом для кавитационного синтеза алмазов являются твердые частицы углерода (аморфный углерод, графит). Они могут играть роль центров формирования пузырьков, а при схлопывании кавитационных пузырьков также превращаться в алмазы. Эти частицы довольно распространены в лаве вулкана Толбачик, и их изотопный состав углерода, по нашим данным, соответствует изотопному составу микроалмазов. Наличие восстановленных форм углерода во флюиде требует преобладания восстановительных условий среды. Акцессорная минерализация, сопровождающая алмазы Толбачинского извержения, содержит самородные $\mathrm{Fe}$ и $\mathrm{Cu}$ и даже металлический $\mathrm{Al}$, которые были найдены в виде пятен на поверхности кристаллов алмаза (Силаев и др., 2015; Карпов и др., 2014). Авторы этих работ рассматривают минералогические и петрографические особенности алмазоносных вулканических пород Толбачика в качестве индикаторов восстановительных условий минералообразования.

Существуют явные свидетельства того, что динамика флюида сыграла роль в синтезе алмазов Толбачика. Алмазы были обнаружены во флюидных включениях пористой лавы, но отсутствуют в плотной лаве того же минерального состава. Алмазы наблюдались только в продуктах первой взрывной фазы извержения: в лаве ранней стадии и пирокластическом материале, выброшенном вместе с газом и флюидом. Есть признаки того, что средой, в которой кристаллизуется алмаз, являются насыщенные летучими соединениями расплавы или флюиды. В свое время, мы были, по-видимому, первыми, кто показал, что среди микроэлементов, содержащихся в алмазах в виде примеси, преобладают те, которые концентрируются во флюидной фазе. Это - водород, азот, соединения углерода, галогены, благородные газы ( $\mathrm{He}, \mathrm{Ne}, \mathrm{Ar})$ и такие летучие элементы, как Ag, Sb, As (Galimov et al., 1985). На возможную роль флюида в образовании алмазов указывали и другие авторы (Каминский, 1994; Boyd et al., 1994; Navon, 1999; Wirth and Rocholl, 2003).

Генезис алмаза в условиях низких приповерхностных давлений считался невозможным, из-за неизбежного термоокисления и растворения алмаза в горячей лаве. В этой связи следует отметить, что адиабатическое охлаждение является особенностью процесса кавитационного синтеза алмазов. Было показано, что твердое вещество, сжатое в процессе коллапса кавитационного пузырька, после сброса давления подвергается немедленному адиабатическому охлаждению из-за возбуждения обратной ударной волны (Galimov, 1973). Это предохраняет синтезированный алмаз от графитизации.

\section{ЗАКЛЮЧЕНИЕ}

Таким образом, мы связываем генезис микроалмазов из лавы и пепла вулкана Толбачик с гидродинамикой процесса извержения. Алмаз формируется в условиях кавитации, которая возникает в стремительном потоке расплавов и флюидов, сопровождающих извержение.

Этот механизм, на наш взгляд, может иметь универсальное значение. Следует отметить, что в процессе синтеза алмазов стадия нуклеации имеет решающее значение. Возникновение новой фазы требует достижения условий ее термодинамической стабильности. Если зародыш уже имеется, алмаз легко растет даже в метастабильных условиях. Например, есть опыт получения алмаза в газовой фазе при давлении ниже атмосферного - эпитаксиаль- 
ное наращивание алмаза (Deryagin et al., 1970). Кавитационный механизм обеспечивает процессе начальной нуклеации, в том числе при низкой исходной концентрации углерода в среде. Процесс образования крупного алмаза - это длительный, иногда многоступенчатый процесс. Изучение распределения изотопов внутри кристаллов алмаза показывает, что в процессе роста алмаза источник углерода может меняться (Galimov, 1971). При извержении вулкана мы имеем дело с относительно коротким одноактным процессом, который приводит к образованию примитивных нано- и микроалмазов. Кроме того, короткие, но мощные импульсы флюида могут происходить во многих геологических процессах. Возможно поэтому, микроалмазы гораздо более распространены в природных условиях, чем это предполагалось ранее.

Исследование выполнено за счет финансовых средств гранта Российского научного фонда (проект № 14-17-00792).

\section{СПИСОК ЛИТЕРАТУРЫ}

Волынец А.О., Мельников Д.В., Якушев А.И. (2013) Первые данные о составе продуктов Трещинного Толбачинского извержения им. 50-летия ИВиС (Камчатка). Докл. РАН 452(3), 303-307.

Гордеев Е.И., Карпов Г.А., Аникин Л.П., Кривовичев С.В., Филатов С.К., Антонов А.В., Овсянников А.А. (2014) Алмазы в лавах трещинного Толбачинского извержения на Камчатке. Докл. РАН 454(2), 204-206.

Зельдович Я.Б., Райзер Ю.П. (1966) Физика ударных волн и высокотемпературных гидродинамических явлений. М.: Наука.

Каминский Ф.В. (1984) Алмазоносность некимберлитовых магматических пород М.: Недрa, $174 \mathrm{c}$.

Карпов Г.А., Аникин Л.П., Флеров Г.Б., Чубаров В.М., Дунин-Барковский Р.Л. (2014) Минералого-петрографические особенности алмазосодержащих продуктов трещинного Толбачинского извержения 2012-2013 гг. В материалах конференции "Вулканизм и связанные с ним процессы”, Петропавловск-Камчатский, ИВ и С ДВО РАН, $1-6$.

Силаев В.И., Карпов Г.А., Ракин В.И., Аникин Л.П., Васильев Е.А., Филиппов В.Н., Петровский В.А. (2015) Алмазы в продуктах трещинного Толбачинского извержения 2012-2013 гг. Камчатка. Вестник Пермского унив. геол., 26, 7-22,

Boyd S.R., Pineau F., Javoy M. (1994) Modeling the growth of natural diamonds. Chem. Geology 116, 29-42.

Cartigny P., Stachel T., Harris J.W., Javoy M. (2004) Constraining diamond metasomathic growth using $\mathrm{C}$ - and N-stable isotopes: examples from Namibia. Litos 77, 359373.
Cartigny P. (2010) Mantle-related carbonados? Geochemical insights from diamonds from the Dachine komatiite (French Guiana). Earth Planet. Sci. Lett. 296, 329-339.

Dawson J.B. (1980) Kimberlites and their xenoliths (Springer-Verlag, Berlin, Heidelberg, New York) 250 p.

Deryagin B.V., Fedossev D.V. (1970) Epitaxial Synthesis of Diamond in the Metastable Region. Rus. Chem. Rev. 39(9), 783-788.

Dnestrovski A.Yu., Voropaev S.A., Ponomareva E.A. (2011) Modelling of conditions of diamond formation under cavitation in benzene. Doklady RAS 436, 611-614.

Erskine D.J, Nellis W.J. (1991) Shock-induced martensitic phase-transformation of oriented graphite to diamond. Nature 349, 317-319.

Haggerty S.E. (1986) Nature 320, 34-38.

Galimov E.M. (1973) On possibility of natural diamond synthesis under conditions of cavitation, occurring in a fastmoving magmatic melt. Nature 243, 389-391.

Galimov E.M. (1985) Some evidence for the feasibility of cavitation diamond synthesis in nature. Geochem. International 22, 456-471.

Galimov E.M. (1991) Isotope fractionation related to kimberlite magmatism and diamond formation. Geochim. Cosmochim. Acta 55, 1697-1708.

Galimov E.M., Kaminskiy F.V., Kodina L.A. (1985) New data on carbon isotope composition of carbonado. Geochem. Intern. 22, 723-726.

Galimov E.M., Kudin A.M., Skorobogatskii V.N., Plotnichenko V.G., Bondarev O.L., Zarubin B.G., Strazdovskii V.V., Aronin A.S., Fisenko A.V., Bykov I.V., Barinov A.Yu. (2004) Experimental corroboration of the synthesis of diamond in the cavitation process. Doklady $R A S$ 49(3), 150-153.

Galimov E.M., Sevastyanov V.S., Karpov G.A., Kamaleeva A.I., Kuznetsova O.I., Konopleva I.V., Vlasova L.N. (2015) Hydrocarbons from volcanic area. Oil seepages in the caldera Uzon, Kamchatka. Geochemistry International, 12, 1-9. Frank F.C., Lang A.R. (1973) Cavitation as a mechanism for the synthesis of natural diamonds. Nature 246, 143-144. Kaminskiy F.V. (1994) Carbonado and yakutite: property and possible genesis, in: Proceedings of the 5-fth International kimberlite conf. (Brazil, v. 2, 1994) p. 136-143.

Navon O. (1999) Diamond formation in the Earth's mantle. in: Proceedings of the 7-th International kimberlite conference, Gurney et al. Eds. (Cape Town) 584-604.

Perchuk L., Ryabchikov I.D., Kushiro I. (1983) in: Proceedings of the 1-st Intern. Symposium Hydrothermal reactions, Sli Somiya, Ftikyu-Kai, Eds. (Tokyo, 1983) p. 258.

Ukhanov A.V., Malysheva T.V. (1973) Heating of ultrabasic xenoliths in kimberlite magma according to Mössbauer spectra of ${ }^{57} \mathrm{Fe}$ in orthopyroxenes. Geochem. International 10, 1467-1472.

Vinogradov A.P., Kropotova O.I., Orlov Y.L., Grinenko V.A. (1966) Isotopic composition of diamond and carbonado crystals. Geochem. Intern. 3, 1123-1125.

Wirth R., Rocholl A. (2003) Nanocrystalline diamond from the Earth's mantle underneath Hawaii. Earth Planet Sci. Lett. 211, 357-369. 